\title{
Spirituality As A Protection Factor Against Suicide In Patients With Bipolar Disorder
}

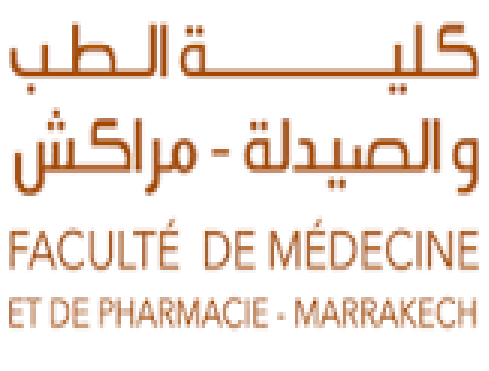

A.BOUALAME, FZ.ELFAHIRI, I.ADALI, F.MANOUDI, F.ASRI

Research team for mental health; psychiatry department,

Mohammed VI University Hospital, Marrakesh, Morocco

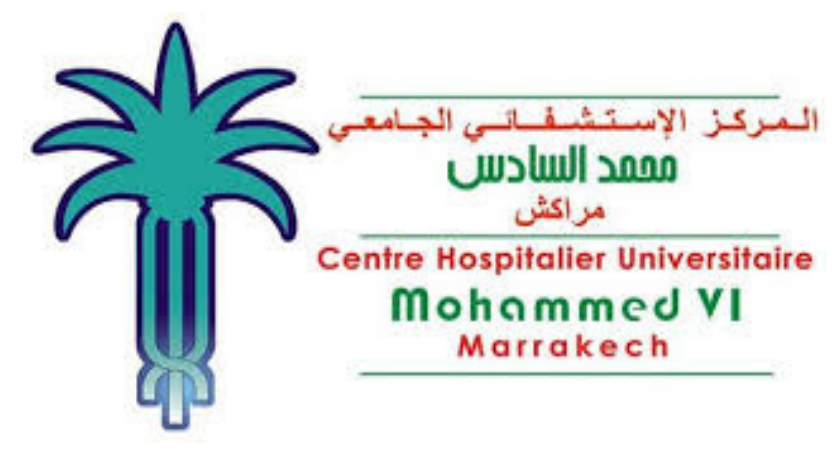

\section{INTRODUCTION}

Patients with bipolar disorder are at high risk of suicide. $20 \%$ to $56 \%$ of these patients will attempt suicide in their lifetime and $10 \%$ to $15 \%$ will die by suicide [1]. While the assessment of suicidal risk is mainly based on the study of some well-defined risk factors, resilience factors -especially spirituality- remain to date an unexplored field of research in this population.

Objective: study of risk and protection factors of suicide in bipolar patients in order to propose appropriate therapeutic and prevention strategies.

\section{METHODS}

Cross-sectional and retrospective study (case-control). We included all patients suffering from bipolar disorder in euthymic phase (3 months at least after remission) hospitalized or seen in consultation in the university psychiatric department Marrakesh- Morocco between January 2017 and December 2017.

A case was defined as any patient with a DSM-IV diagnosis of bipolar disorder with a recent suicidal attempt or in his antecedents.

The evaluation of all the patients focused on sociodemographic, clinical and psychological factors (using the intrinsic spirituality scale -ISS- for spirituality but also Birchwood scale for insight, and Rosenberg for self-esteem).

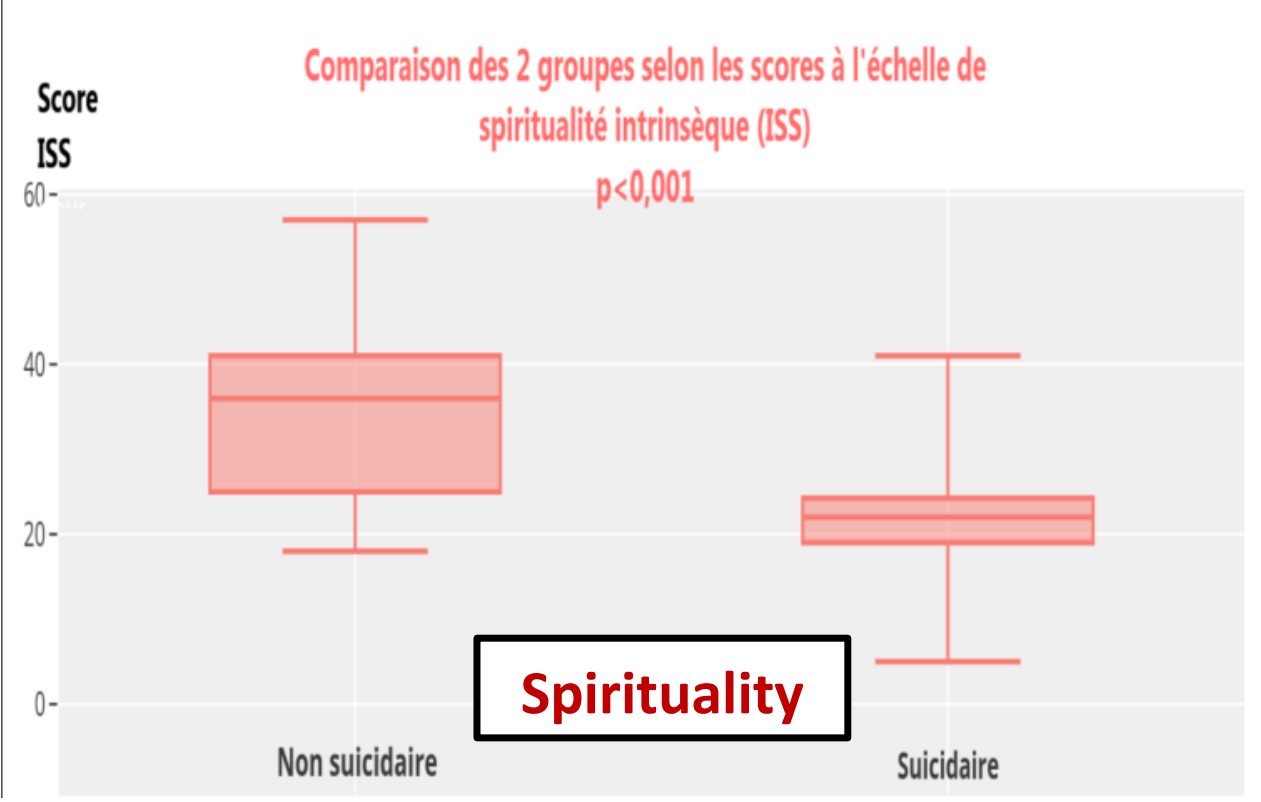

\section{RESULTS}
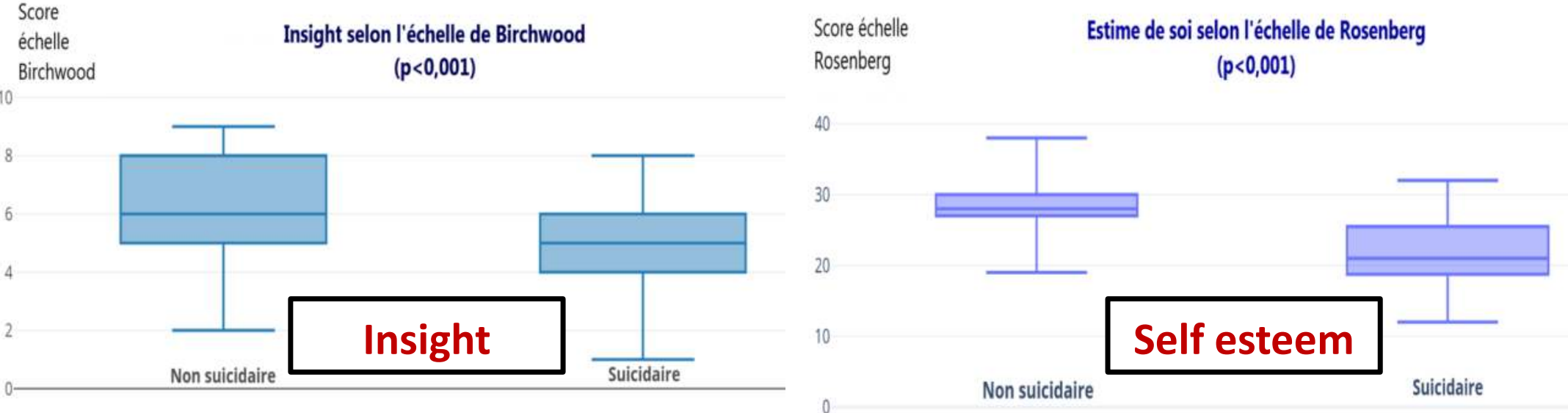

75 patients were included, 25 of whom were suicidal. The mean age of the patients was 34 years, $68 \%$ of the patients were female, $80 \%$ had a type I disorder, the duration of the illness was 8.73 years on average. Suicidality (recent or old SA) was significantly correlated with alcohol and tobacco use $(p=0.009$ and $p=0.002$ respectively), type II bipolar disorder $(p<0.001)$ and a higher number of depressive episodes $(p<0.001)$.

Higher scores on the scales of spirituality, insight, and self-esteem were significantly correlated with lack of suicidality ( $p<0.001$ for all three variables).

As for pharmacological management prior to hospitalization, we found no difference between the two groups regardless of the molecule used. However, discontinuation and poor adherence were correlated with suicidal risk $(p=0.015)$.

\section{CONCLUSION}

Our study shows that resilience factors such as spirituality are important considerations in the assessment and management of a bipolar patient.

Management strategies targeting, among other things, the empowerment of resilience factors could be an important lever in the prevention of suicidal behavior in patients suffering from bipolar disorder.

\section{References}

\footnotetext{
1. Costa L da S, Alencar ÁP, Neto PJN, Santos M do SV dos, da Silva CGL, Pinheiro S de FL, et al. Risk factors for suicide in bipolar disorder: A systematic review. Journal of Affective Disorders. 2015 Jan 1;170:237-54.

2. David R. Hodge MCS, MSW (2003) The Intrinsic Spirituality Scale, Journal of Social Service Research, 30:1, 41-61, DOI: 10.1300/J079v30n01_03

3. Bourgeois ML. Insight et conscience de la maladie en psychopathologie. EMC Psychiatrie. 2010;37.

4. Bridge JA, Goldstein TR, Brent DA. Adolescent suicide and suicidal behavior. Journal of child psychology and psychiatry. 2006 Mar;47(3-4):372-94.
}

\begin{tabular}{|c|c|c|c|c|}
\hline 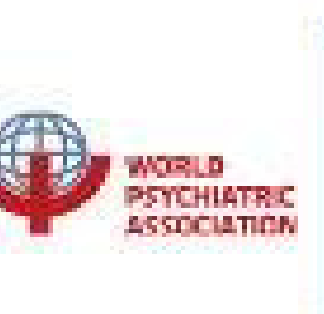 & ES: & 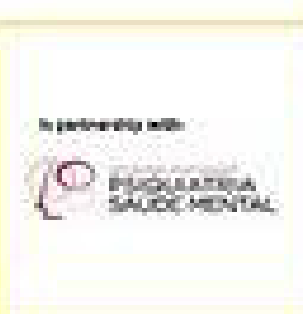 & 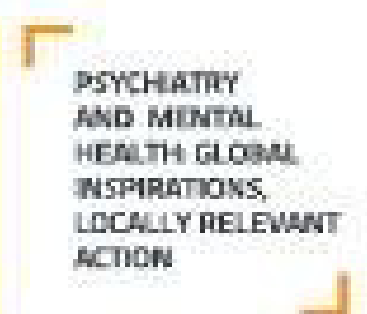 & $\begin{array}{l}19^{\text {TH }} \text { WPA WORLD } \\
\text { CONGRESS OF } \\
\text { PSYCHIATRY }\end{array}$ \\
\hline
\end{tabular}

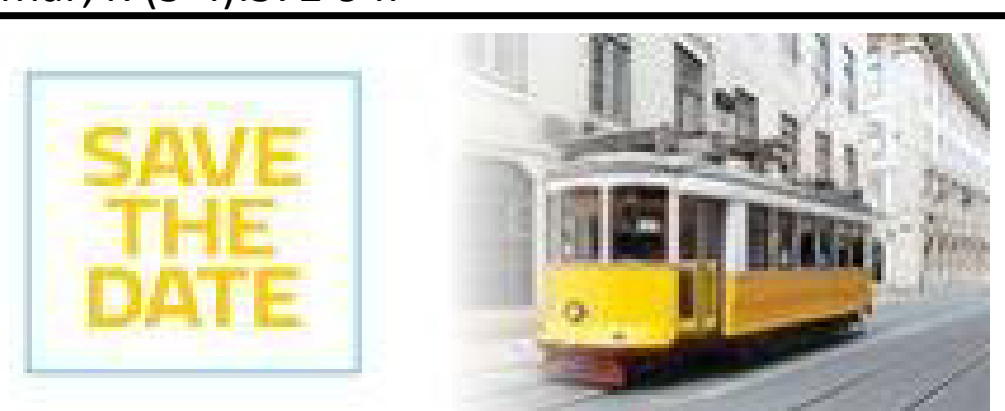

